\title{
CSF Studies Facilitate DNA Diagnosis in Familial Alzheimer's Disease Due to a Presenilin-1 Mutation
}

\author{
Susanne T. de Bot ${ }^{a, *}$, H.P.H. Kremer ${ }^{\mathrm{a}}$, Dennis Dooijes ${ }^{\mathrm{c}}$ and Marcel M. Verbeek ${ }^{\mathrm{a}, \mathrm{b}}$ \\ ${ }^{a}$ Department of Neurology, Donders Centre for Brain Cognition and Behaviour, Radboud University Nijmegen \\ Medical Centre, Nijmegen, the Netherlands \\ ${ }^{\mathrm{b}}$ Laboratory of Pediatrics and Neurology, Alzheimer Centre Nijmegen, Nijmegen, the Netherlands \\ ${ }^{\mathrm{c}}$ Department of Clinical Genetics, Erasmus Medical Center, Rotterdam, the Netherlands
}

Communicated by Sanna-Kaisa Herukka

\begin{abstract}
In sporadic Alzheimer's disease (AD), cerebrospinal fluid (CSF) analysis is becoming increasingly relevant to establish an early diagnosis. We present a case of familial AD due to a presenilin-1 mutation in which CSF studies suggested appropriate DNA diagnostics. A 38 year old Dutch man presented with dementia, spastic paraparesis, and frontal executive function impairments, mimicking familial Creutzfeldt Jakob disease and frontotemporal dementia. CSF studies, revealing increased total tau and phosphorylated-tau levels with decreased amyloid- $\beta_{42}$, distinguished familial AD from Creutzfeldt Jakob disease and frontotemporal dementia. A causative p.L424R PSEN1 mutation was subsequently identified.
\end{abstract}

Keywords: Amyloid- $\beta_{42}$, cerebrospinal fluid biomarkers, familial Alzheimer's disease, phosphorylated-tau, p.L424R, presenilin-1 mutation, tau protein

\section{INTRODUCTION}

The ante mortem diagnosis of Alzheimer's disease (AD) has traditionally been based on clinical criteria that have insufficient sensitivity in the early phases (AD pathology is often present years before clinical symptoms appear) and lack specificity [1,2]. In the last decennium, however, cerebrospinal fluid (CSF) diagnostic studies have been established as an important tool for an early and specific differential diagnosis of dementia syndromes [2-4]. Combined analysis of CSF biomarkers results in higher specificity and sensitivity

* Corresponding author: Susanne T. de Bot, MD, Department of Neurology, Radboud University Nijmegen Medical Centre, PO box 9101, 6500 HB, Nijmegen, The Netherlands. Tel.: +31 24 3618860; Fax: +31 24 3541122; E-mail: ST.Bot@ neuro.umcn.nl. than clinical criteria alone in distinguishing $\mathrm{AD}$ from Creutzfeldt-Jakob disease (CJD), frontotemporal dementia (FTD), vascular dementia, dementia with Lewy bodies (DLB), and Parkinson's disease dementia [3,4]. The most important CSF biomarkers for these various dementia-associated disorders are presented in Table 1.

Also in cases of clinical mild cognitive impairment, decreased CSF levels of $\mathrm{A} \beta_{42}$, together with elevated total-tau and phosphorylated-tau concentrations, helped to predict the conversion to AD [5].

In patients with early-onset or familial Alzheimer's disease (FAD), a diagnosis is usually made according to clinical criteria, a positive family history with multiple affected members, and by DNA testing. Currently, three autosomal dominant inherited genes have been identified: the amyloid- $\beta$ precursor protein $(A \beta P P)$ gene on chromosome 21; the presenilin-1 (PSEN1) 
Table 1

CSF biomarkers in different dementia syndromes

\begin{tabular}{|c|c|c|c|}
\hline $\begin{array}{l}\text { Reference values according } \\
\text { to the patient's age: }\end{array}$ & $\begin{array}{c}\mathrm{A} \beta_{42} \text { levels }(\mathrm{ng} / \mathrm{L}) \\
\text { age }<15: n>400 \\
\text { age }>15: n>500\end{array}$ & $\begin{array}{c}\text { t-tau }(\mathrm{ng} / \mathrm{L}) \\
\text { age } 15-50: n<300 \\
\text { age } 51-85: n<350\end{array}$ & $\begin{array}{c}\text { p-tau181 }(\mathrm{ng} / \mathrm{L}) \\
\text { age }>15: n<85\end{array}$ \\
\hline Alzl & $\downarrow \downarrow$ & $\uparrow \uparrow$ & $\uparrow \uparrow$ \\
\hline Creu & $\downarrow$ & $\uparrow \uparrow \uparrow>$ & $\mathrm{N}$ \\
\hline Frontotemporal dementia & $\mathrm{N} /(\downarrow)$ & varia & $N / \uparrow$ \\
\hline Vascular dementia & $\mathrm{N} /(\downarrow)$ & $\mathrm{N} /(\uparrow)$ & $\mathrm{N}$ \\
\hline Dementia with Lewy bodies & $\downarrow$ & & $\mathrm{N}$ \\
\hline \multicolumn{4}{|c|}{$\begin{array}{l}\mathrm{N} \text { : normal, } \uparrow \text { : increased, } \downarrow \text { : decreased, } \mathrm{A} \beta_{42} \text { : amyloid } \beta_{42} \text { protein; t-tau: total tau; } \mathrm{p} \text {-tau 181: tau } \\
\text { phosphorylated at threonine } 181 \text {. } \\
\text { For determination of reference values of } \mathrm{A} \beta_{42} \text {, total tau and p-tau levels, patients were included } \\
\text { with ages below } 50 \text { years }(n=129) \text { and with ages } 50-85 \text { years }(n=50) \text {, who were referred } \\
\text { to the Department of Neurology and underwent a lumbar puncture in a diagnostic work-up, but } \\
\text { who, after extensive examination, turned out not to have a neurological disease, and who had } \\
\text { normal CSF cell count, hemoglobin, bilirubin, total protein, lactate, glucose, and no oligoclonal } \\
\text { IgG bands [4]. Comparable values were published by Sjogren et al. [18]. }\end{array}$} \\
\hline
\end{tabular}

gene on chromosome 14; and the presenilin-2 (PSEN2) gene, on chromosome 1 . More than $50 \%$ of FAD cases can be ascribed to a PSEN1 mutation, with more than 160 different mutations having already been identified (http://www.molgen.ua.ac.be/Admutations) [6]. The fact that PSEN1 associated dementia is genetically and clinically heterogeneous can hamper an appropriate diagnosis. The following case report demonstrates that CSF biomarker analysis may facilitate this diagnosis and may allow a rapid selection of relevant and conclusive mutation analysis.

\section{CASE REPORT}

A 38 year old man was referred to the outpatient clinic with progressive memory complaints and gait difficulties for 8-9 months. The patient himself denied memory problems but his relatives had noticed incipient memory impairment. The patient had recently given up his job as a security officer in a private company. His father recognized these signs as similar to those of his deceased wife, who started having cognitive decline and gait difficulties at the age of 35 . She had died at the age of 39, severely demented, wheel-chair bound, and suffering from epilepsy and hallucinations. The grandfather of the index-patient, who suffered from a similar disease, had died in his late thirties.

On neurological examination the index-patient revealed bradyphrenia, mild impairment of executive functions such as decreased initiation and selfgeneration, a slurred speech, leg hypertonia, and symmetric brisk reflexes that were more pronounced in the lower extremities, with bilateral Babinski sign. His gait was both spastic and ataxic. The Mini Mental State Examination (MMSE) score was 24/30.
The following autosomal dominant (AD) degenerative diseases were considered in the differential diagnosis: familial CJD, FTD, FAD, and hereditary spastic paraparesis with cognitive impairment (SPAST).

Routine hematological and serum biochemical studies were all normal. Brain magnetic resonance imaging revealed bilateral posterior parietofrontal atrophy, without white matter abnormalities (Fig. 1).

CSF was obtained by lumbar puncture, collected in polypropylene tubes, and transferred to the hospital laboratory within 30 minutes. Routine analysis revealed a normal leukocyte count and a slightly elevated protein concentration $(598 \mathrm{mg} / \mathrm{L}$ ) (reference range: 240 $490 \mathrm{mg} / \mathrm{L}$ ). After centrifugation, small aliquots of the CSF were frozen at $-80^{\circ} \mathrm{C}$ until analysis of $\mathrm{A} \beta_{42}$, total tau, and phosphorylated tau (p.Thr181) (p-tau) protein (using commercial assays, Innogenetics, Gent, Belgium). These analyses showed an increased p-tau concentration ( $217 \mathrm{ng} / \mathrm{L}$; reference range $<85 \mathrm{ng} / \mathrm{L})$ and increased total tau protein concentration $(1382 \mathrm{ng} / \mathrm{L}$; reference range $<300 \mathrm{ng} / \mathrm{L})$; whereas the $\mathrm{A} \beta_{42}$ concentration was decreased $(380 \mathrm{ng} / \mathrm{L}$; reference range $>500 \mathrm{ng} / \mathrm{L})$. For the establishment of reference values of $\mathrm{A} \beta_{42}$, total tau, and $\mathrm{p}$-tau levels, see the legend of Table 1.

Whole gene sequencing of the PRNP (for familial CJD), MAPT (for FTD), and SPAST genes revealed no mutations. Sequencing of the PSEN1 gene identified the p.L424R (NM_000021.2: c.1271T $>$ G, p.Leu424Arg) missense mutation in exon 12. After identifying this PSEN1 mutation, PSEN2 and $A \beta P P$ (less frequent forms of FAD) analysis was considered redundant. 

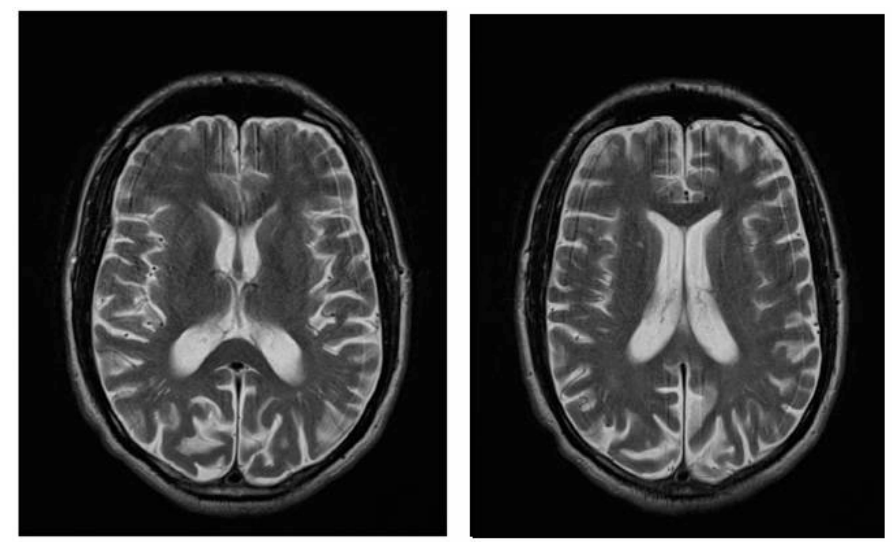

A

B

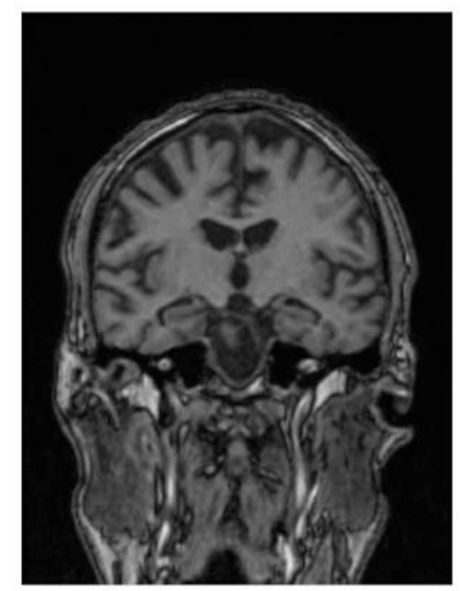

$\mathrm{C}$

Fig. 1. Cerebral magnetic resonance imaging of the patient described: A + B transversal images: bilateral posterior parietofrontal atrophy, without white matter abnormalities; C: coronal image: bilateral parietofrontal and temporal atrophy.

\section{DISCUSSION}

In the more than 160 mutations in the PSEN1 gene that are currently known to cause FAD, many different signs and symptoms may accompany early onset dementia [6, (http://www.molgen.ua.ac.be/Admutations)]. The following have been reported: myoclonus, generalized epileptic seizures, psychiatric disturbances, frontal executive function impairments, spastic paraparesis, extrapyramidal and cerebellar signs, and early onset aphasia with relatively spared naming skills $[7,8]$. In individual cases, the clinical distinction between FAD and familial CJD or between FAD and FTD may be difficult [8]. Hereditary spastic paraparesis with cognitive impairment is described as a complicated form of SPAST [9]. This autosomal dominant disorder can also resemble FAD with spastic paraparesis in the beginning of the disease. Because the cognitive decline in SPAST (which may be present before the onset of spastic paraparesis) is usually relatively mild, a rapidly progressive dementia would reject this differential diagnose. In this case, a diagnosis of SPAST associated disease was rejected, considering the rapidly progressive dementia of the mother.

A patient such as ours, who presents with such an extensive autosomal dominant neurodegenerative disease, requires consideration of at least four different diagnoses with subsequent costly and time consuming (4-6 months) sequencing efforts in four (or more) different genes. Clearly, ancillary investigations such as CSF studies (which may be obtained in less than two weeks) may aid in selecting appropriate priorities for 
gene sequencing efforts. In retrospect, the CSF abnormalities we found, interpreted as being typical for $\mathrm{AD}$, should have suggested to us to initially restrict our DNA diagnostic resources to PSEN1 mutation analysis or mutation analysis of other genes involved in AD.

CSF biomarkers abnormalities have been demonstrated before in a few studies of presymptomatic carriers of PSEN1 mutations. In a study with six asymptomatic PSEN1 mutation carriers, very low CSF A $\beta_{42}$ levels where demonstrated [10]. In another report a PSEN1 patient was described presenting with mild cognitive impairment and later developing probable $\mathrm{AD}$, without other neurological signs [11]. This patient had elevated CSF total tau and p-tau concentrations. Recently, all three biomarkers were evaluated in preclinical PSEN1 mutation carriers compared to non-mutation carriers, showing a reduced $\mathrm{A} \beta_{42}$ to $\mathrm{A} \beta_{40}$ ratio in CSF together with elevated CSF total tau and p-tau concentrations [12]. Our patient represents an already symptomatic case, where these AD specific CSF biomarkers alterations preceded DNA results and demonstrated their use in distinguishing a clinical diagnosis of PSEN1 FAD from familial CJD and FTD.

The p.L424R (p.Leu424Arg) missense mutation in exon 12 has been described as a pathogenic mutation previously, in one family from Poland [13]. Our patient had a similar age of onset (30-35 years) and his mother had a similar progression to death ( $4-5$ years) as in the described family. In contrast, these published cases had typical AD, without additional neurological deficits. Our family with a p.L424R mutation revealed a much more diverse phenotype, with spastic paraparesis, frontal executive function impairment, epilepsy, and psychiatric symptoms all occurring in one family. In contrast to the p.L424R mutation, the p.L424H (p.Leu424His) mutation has been found more often, for example in a French family and in a Polish family $[14,15]$. The last one is associated with a clinical phenotype of variant $\mathrm{AD}$ with strong FTD signs, like frontal deficits, personality changes and social inhibition, and some DLB signs, such as early visual hallucinations [15]. Another Leu424Phe (p.L424F) mutation was found in a Bulgarian family with marked behavioral abnormalities with dementia and an age of onset around 60 years [16]. This strongly suggests that other genetic and epigenetic and possibly environmental factors may contribute to phenotypic heterogeneity in PSEN1 associated FAD. Apparently, the actual localization of the mutation within the PSEN1 gene appears largely unpredictive for the resulting phenotype, thus demonstrating a lack of genotype-phenotype correlation in PSEN1 associated disease [17].
Although no functional studies have been performed on the p.L424R mutation, it is considered pathogenic. The p.L424R and p.L424H mutations were not present in a panel of 400 Dutch control chromosomes (D. Dooijes, unpublished). P.L424R has been previously described to be completely segregated with FAD in a large Polish family [13]. The PSEN1 p.L424H/F mutations, described in another Polish FAD family, a French family, and a Bulgarian family, affects the same Leucine amino acid residue at position 424 of the PSEN1 protein that is affected by the p.L424R mutation [14-16]. P.Leu424 is located in exon 12 which encodes a structurally conserved and a functionally important domain in which various pathogenic mutations have been described. This leucine residue is located in a critical region of the transmembrane domain of the PSEN1 protein. By modeling the impact of a substitution on this transmembrane domain and by using control groups, silent polymorphisms could successfully be discriminated from disease-causing mutations [15]. Furthermore, a computer prediction algorithm predicts both the p.L424R mutation and the p.L424H mutation to be pathogenic (http://sift.jcvi.org/).

\section{ACKNOWLEDGMENT}

This work was supported by a grant from ZON-MW Innovational Research (number 917.46.331, "Vidi program”, to MMV).

\section{REFERENCES}

[1] McKhann G, Drachman D, Folstein M, Katzman R, Price D, Stadlan EM (1984) Clinical diagnosis of Alzheimer's disease: report of the NINCDS-ADRDA Work Group under the auspices of Department of Health and Human Services Task Force on Alzheimer's Disease. Neurology 34, 939-944.

[2] Dubois B, Feldman HH, Jacova C, DeKosky ST, BarbergerGateau P, Cummings J, Delacourte A, Galasko D, Gauthier S, Jicha G, Meguro K, O’brien J, Pasquier F, Robert P, Rossor M, Salloway S, Stern Y, Visser PJ, Scheltens P (2007) Research criteria for the diagnosis of Alzheimer's disease: revising the NINCDS-ADRDA criteria. Lancet Neurol 6, 734-746.

[3] Lewczuk P, Wiltfang J (2008) Neurochemical dementia diagnostics: State of the art and research perspectives. Proteomics 8, 1292-1301.

[4] De Jong D, Kremer HPH, Olde Rikkert MGM, Verbeek MM (2007) Current state and future directions of neurochemical biomarkers for Alzheimer's disease. Clin Chem Lab Med 45, 1421-1434

[5] Diniz BS, Pinto JA Jr, Forlenza OV (2007) Do CSF total tau, phosphorylated tau, and beta-amyloid 42 help to predict progression of mild cognitive impairment to Alzheimer's disease? A systematic review and meta-analysis of the literature. World J Biol Psychiatry 13, 1-11. 
[6] Karlstrom H, Brooks WS, Kwok, JB, Broe GA, Kril JJ, McCann H, Halliday GM, Schofield PR (2008) Variable phenotype of Alzheimer's disease with spastic paraparesis. $\mathrm{J} \mathrm{Neu}$ rochem 104, 573-583.

[7] Larner AJ, Doran M (2006) Clinical phenotypic heterogeneity of Alzheimer's disease associated with mutations of the presenilin-1 gene. J Neurol 253,139-158.

[8] Menéndez M (2004) Pathological and clinical heterogeneity of presenilin 1 gene mutations. J Alzheimers Dis 6, 475-482.

[9] McMonagle P, Byrne P, Hutchinson M (2004) Further evidence of dementia in SPG4-linked autosomal dominant hereditary spastic paraplegia. Neurology 62, 407-410.

[10] Moonis M, Swearer JM, Dayaw MP, St George-Hyslop P, Rogaeva E, Kawarai T, Polen DA (2005) Familial Alzheimer disease: decreases in CSF Abeta42 levels precede cognitive decline. Neurology 65, 323-325.

[11] Matsushita S, Arai H, Okamura N, Ohmori T, Takasugi K, Matsui T, Maruyama M, Iwatsubo T, Higuchi S (2002) Clinical and biomarker investigation of a patient with a novel presenilin-1 mutation (A431V) in the mild cognitive impairment stage of Alzheimer's disease. Biol Psychiatry 52, 907-910.

[12] Ringman JM, Younkin SG, Practico D, Seltzer W, Cole GM, Geschwind DH, Rodriquez-Agudelo Y, Schakker B, Fein J, Sokolow S, Rosario ER, Gylys KH, Varpetian A, Medina LD, Cummings JL (2008) Biochemical markers in persons with preclinical familial Alzheimer disease. Neurology 71, 85-92.

[13] Kowalska A, Forsell C, Florczak J, Pruchnik-Wolinska D, Modestowicz R, Paprzycki W, Wender M, Lannfelt L (1999)
A Polish pedigree with Alzheimer's disease determined by a novel mutation in exon 12 of the presenilin 1 gene: clinical and molecular characterization. Folia Neuropathol 37, 57-61.

[14] Raux G, Guyant-Maréchal L, Martin C, Bou J, Penet C, Brice A, Hannequin D, Frebourg T, Campion D (2005) Molecular diagnosis of autosomal dominant early onset Alzheimer's disease: an update. J Med Genet 42, 793-795.

[15] Zekanowski C, Golan MP, Krzysko KA, LipczynskaLojkowska W, Filipek S, Kowalska A, Rossa G, Peplonska B, Styczynska M, Maruszak A, Religa D, Wender M, Kulczychi J, Barcikowska M, Kuznicki J. et al.(2006) Two novel presenilin 1 gene mutations connected with frontotemporal dementia-like clinical phenotype: genetic and bioinformatic assessment. Exp Neurol 200, 82-88.

[16] Mehrabian S, Traykov LT, A. Jordanova A, Rademakers R, Cruts M, Raycheva MR, Van den Broeck M, Kremensky I, Van Broeckhoven C (2006) Novel PSEN1 gene mutation in a large Bulgarian pedigree with Alzheimer's disease and atypical phenotype. Eur J Neurol 13(suppl2), p41 (abstract SC336).

[17] Larner AJ (2004) Genotype-phenotype correlation in earlyonset Alzheimer disease with presenilin 1 gene mutations. Arch Neurol 61, 801.

[18] Sjögren M, Vanderstichele H, Agren H, Zachrisson O, Edsbagge M, Wikkels $\varnothing$ C, Skoog I, Wallin A, Wahlund LO, Marcusson J, Nägga K, Andreasen N, Davidsson P, Vanmechelen E, Blennow K (2001) Tau and Abeta42 in cerebrospinal fluid from healthy adults 21-93 years of age: establishment of reference values. Clin Chem 47, 1776-1781. 